\title{
Status of Curriculum Mapping of Undergraduate Medical Programmes in South Africa
}

\author{
Gerda C. Botha and Adegoke O. Adefolalu
}

\begin{abstract}
Curriculum mapping in medical education allows for quick determination whether the curriculum meets the required standards and if its contents are aligned with the learning outcomes. This ensures the curriculum stays relevant, producing graduates capable of addressing the health needs of the institution's host community. The status of curriculum mapping of the undergraduate medical programmes in South African medical schools was not documented in the literature at the time of this research. This study aimed to describe the current status of curriculum mapping of undergraduate medical programmes in South Africa. A qualitative study was conducted among the academic managers from all the eight medical schools in 2015. Semi-structured interviews were used to collect data from fourteen participants who were purposefully sampled, and data analysis was done by inductive thematic analysis after coding and verbatim transcriptions. None of the medical schools had a fully developed mapping platform, however they all possessed various guides and matrices that contained components of their curricula which were mainly used for accreditation purposes. In addition, they all had strategies in place for reviewing their curricula, although some of the institutions were at different stages of developing their own mapping platforms. The challenges described by the institutions as barriers to curriculum review appeared to be related to lack of a proper curriculum mapping process. In conclusion, curriculum mapping was in infancy stage at the time of this research in South Africa, the medical schools that were in the process or about to develop electronic mapping platforms had no uniform outcome framework. Future research on the features of the mapping platforms developed by all the institutions is highly recommended.
\end{abstract}

Index Terms - Curriculum mapping; Medical curriculum; Mapping platforms; Undergraduate programmes.

\section{INTRODUCTION}

Curriculum mapping is a visual representation of the different components of the curriculum and is an essential tool of curriculum management that enables the linking of complex, student-centred competencies with course-specific and well-defined objectives [1]-[2]. While the map brings together the different elements of the curriculum, it also makes it more transparent and reduces discrepancy, which allows for the core curriculum to be easily identified and any unplanned duplications to be eradicated. [1]-[3]. Curriculum mapping is very important in the process of curriculum review; a cyclical process that ensures the curriculum stays relevant, allowing it to respond to changes in the society. In addition to the above, curriculum mapping has been shown to be useful in the integration of various stages in medical education programmes in such a way that the exit level outcomes of one phase become the entry requirements for the next. Mapping is also crucial in the quality assurance strategies used in curriculum management of medical programmes, it determines the students' outcome competencies and the required changes to the curriculum, which enables the curriculum contents to be aligned with the outcomes [4]-[6].

The curriculum mapping involved the cross-referencing the various courses within the curriculum, which is followed by explanation of the cumulative contributions of the courses to the established program competencies [7]-[9]. The adoption of a multi-dimensional electronic mapping system has been advocated by various stakeholders in medical education, it is a procedure that is known to enable dynamic mapping and peer-review process, which allows for benchmarking and standards setting among medical schools [9]-[11]. When curriculum content is not aligned with the outcome, the programme outcome-competencies will not translate into graduate attributes expected of the programme [9]. There is enough information in the literature that supports the positive impact of this process, institutions that completed curriculum mapping process have recorded exponential growth in curriculum quality improvement skills among their faculties. In addition, the programme outcome-competencies were also seen to translate into the attributes expected of the programme graduates [10], [13]-[15]. Curriculum mapping has been embraced globally due to its inherent benefits, and mapping of the curriculum to program competencies that in turn lead to continued quality improvement initiatives is now being embraced by a wide number of organizations as a way to demonstrate the linkages between course content and the achievement of program objectives. Furthermore, some medical accreditation bodies have made curriculum mapping a requirement for accreditation purposes with emphasis on its use in curriculum's quality improvement initiatives. There is paucity of information on curriculum mapping in the literature in the context of South Africa medical education [9]. This research was needed to gain better understanding of mapping and its application in medical programmes. Therefore, the current research was aimed at exploring the status of curriculum mapping of medical programmes at undergraduate level in South African universities. 


\section{MethodOlOGY}

A descriptive explorative qualitative research design was used during 2015 to investigate the state of curriculum mapping within the undergraduate medical programmes in South Africa. The aim of the study was to explore the status of curriculum mapping of medical programmes with a view to identify the key elements regarded as important to a mapping platform by the medical schools, together with factors associated with mapping. All the eight medical schools agreed to participate in the study after invitation. A total of 14 participants were purposively sampled, all of whom were curriculum managers or executive deans at their various institutions. Figure 1 below shows the frequency distribution of the participants. Ethical clearance was obtained from the Stellenbosch University's Health Research Ethics Committee (S15/05/123), and Sefako Makgatho Health Sciences University before the study commenced. Permission to conduct the study was also sought and obtained from the various deans of each of the eight medical schools. Data collection was done by semi-structured interviews with a prepared interview guide that contained probing questions. Some interviews were conducted in Afrikaans language, which was later translated. The interviews were recorded, and transcription was done verbatim. All the respondents were interviewed by the same person, this enable the interviewer to have a very good sense of what the emergent themes might be after transcription of the audio recordings. The data analysis was done using inductive thematic analysis after coding, the process begins with manual data analysis by initial coding followed by grouping related codes to form categories with similar categories eventually forming themes; an external coder was used to confirm coding during data analysis [16].

TABLE I: NUMBER OF PARTICIPANTS FROM EACH UNIVERSITY (N=14)

\begin{tabular}{|l|c|c|c|c|c|c|c|c|}
\hline University & U1 & U2 & U3 & U4 & U5 & U6 & U7 & U8 \\
\hline No of participants & 1 & 1 & 1 & 5 & 1 & 1 & 2 & 2 \\
\hline
\end{tabular}

\section{RESULTS}

The interviews centred on stage at which construction of a curriculum map was at the participant's institutions, the elements considered important to a mapping platform, benefits of building maps and challenges associated with curriculum map at respondent's medical school. Participants mainly described the current state of curriculum mapping at their institutions and its place in the future. The three themes that emerged from the analysis of the qualitative data obtained from all the sources are as follows; Curriculum design and documentation; Curriculum review and renewal Strategies; and Challenges associated with curriculum implementation.

\section{A. Theme I: Curriculum Design and Documentation}

All eight institutions indicated that their curricula follow some sort of integrative model, for example problem-based or case/themed-based, during the pre-clinical phase. Some indicated early clinical exposure which gradually increases over the full curriculum period. All curricula make use of clinical block rotations during senior years. They all have documented curriculum information in some format but none of them have a fully fledge curriculum map as defined. These include learning guides, logbooks or case competencies lists for specific units of learning such as clinical blocks or integrated themes. Often, one person takes responsibility for a specific unit of learning (a module/block/theme), but the details are not shared across the programme, although these documents were available to students and accreditation authorities.

Some institutions indicated that they made use of a graphical image in order to provide an overview of the curriculum, specifically to orientate new students and academic staff. Others claimed to have a curriculum document for the pre-clinical phase, but not for the clinical phase, but there seemed to be a sense that a more coherent or complete map of the entire curriculum could have value, as illustrated below:

We literally have a graphical representations of the curriculum presented on one page, it shows the different years and the phases, so you can see which modules forms part of each year - it is some sort of snapshot table showing the structure... (translated U3)

Here at our institution we have not gone through a process of mapping, the closest we get to it is a sort of graphical representation, it cannot really be regarded as a map, but it is at least a simplistic graphical picture of the curriculum for the students to see; at least in a person's brain it is some sort of roadmap, on the structure of the curriculum..(translated U1)

We don't have one big map, but we have lots of mini maps... it is not incorporated into a programme map right now... so there is lots of individual mind maps and varying degrees of it formally been recorded, scattered around, but they're not all drawn together... (U4)

It is all written down week by week, so every week is mapped out for a specific function... and they speak to each other... like we are saying it is a spiral curriculum... the one lead to the other. As you see, we have the programme for this, we have the map for each week and the cases on paper... In the more senior years then they break up into clinical clerkships where they go through their clinical rotations, then it is according to departments, disciplines. (U5)

The best snapshot of any university is the documents they put forward for accreditation visits........the map is really what you are looking for, but in the end you are satisfied with getting a fairly fragmented picture across the programme, the universities are really good at having a little file for each course, so now you get about 65 in a room ... the whole picture exists in parts... (U2)

Some schools have attempted to organize their entire curricula information into one central electronic document such as an expandable disc, however these type of attempts got stalled due to lack of institutional support. Others are exploring the available information on web-based platforms which requires familiarity with specific software; it appeared the schools were making preparation for electronic mapping: 
At a stage we tried to put together some sort of administrative map on a computer system, indicating the number of lectures, tutorials, and seminars, but it is not a tool that is academically useful... (translated U1)

In an attempt to try and address the issue they put together a large map of everything that was being taught in the first three years in relation to the cases... and they made a CD of it and it went around the faculty and everybody got a copy and nobody ever looked at it and so it was a document that existing but it was actually not of much utility and the arguments continued... (U2)

An electronic mapping tool will be useful. I have looked at ones they have internationally, but they are so patchy.... And they tend to be very specific, not one that will conceive about what we are doing. I can't say that I have found anything that I am beginning to understand fully. So what I did was trying to get into this commercial websites, but I could never get very far, and it was very much just objectives and topics based. (U6)

Three medical schools indicated that they had already contacted international partners who would be in collaboration with them on developing their mapping platform. One of them started during 2015 and begins to load curriculum information onto the institutionally adapted platform. The process was described appreciatively and as work still in progress that had not been completed at the time the interview was conducted.

We are privileged to have a web-based curriculum mapping platform from Charite, and we are at this stage uploading all the information... especially from all the preclinical departments, because they have been through a recent self-review and all their learning guides, and PQM documents and so forth are up to date... and to upload it onto LOOOP is a matter of packaging your information... and we are well on our way doing so... it is multidisciplinary, and it also looks at the integration of the curriculum in all the levels, that is from first year to final year... I would say it is work that is continuing... so it is not really completed... (U7)

\section{B. Theme II: Curriculum Review and Renewal Strategies}

All participants indicated that they have structures and strategies in place for academic planning and curriculum review. Each institution referred to these in different terms, although structures seem to include any type of programme, phase or module committee and task team as well as educational unit or specific directorate. A teamwork approach seemed to work well for most of the institutions, especially during the planning phases. Almost all the institutions agreed that the existing structures could be used to drive curriculum mapping, one institution insisted that a sub-committee would be needed to investigate mapping before the programme committee can decide:

My suggestion is that we look at mapping by making use of a team approach. For instance here we have a programme committee in place, where we have representatives of all the phases. We also have for each phase a phase committee where all the module leaders are. We will definitely also have to manage curriculum mapping in this way... (translated U3)

We have the Curriculum Committee... first of all we have the Medical Education Committee as the committee of the faculty who is responsible for all undergraduate teaching and whatever changes we make must be approved by that committee. So that's where we deal with these issues... (U5)

When planning a new module for evidence-based practice, our Centre for Evidence Based Health Care Education had to go through a sort of mapping process and had to sit down to work through the various learning guides to see what happened where... (translated U1)

The programme committee meets on a monthly basis... but there will need to be somebody that can spend more time than that hour long monthly meeting, I think a subcommittee will have to investigate; thereafter the current programme committee can take the final decision and drive the process... (translated U8)

Some institutions indicated that they achieved relative success with processes for planning and reviewing the earlier years of the curriculum, but experienced challenges when it came to the clinical phase. Reasons given for challenges related to curriculum review and renewal in the clinical years mainly focused on change fatigue, lack of interdisciplinary teamwork or whole-school approach, lack of educational knowledge and experience in formulating an integrated curriculum, insufficient engagement, and the inability to define and differentiate core content for the undergraduate programme.

We started curriculum mapping right at the beginning, but one of the challenges was that the process was done in two phases, so there was the so-called pre-clinical phase and the clinical phase. For the pre-clinical phase we had a lot of participation from all the different science disciplines and because they mapped according to a set of cases it actually went quite well. When it got to the clinical disciplines the curriculum mapping process actually got stalled. I think people were already tired by then by 'change this change that' and the clinical disciplines were quite powerful in not implementing major changes; so they pretty much stayed with what they had, each department had their programme, and it kind of carried on... (U2)

... because in our system people tend to teach their own disciplines very much. We were not used to write an overarching integrated curriculum. Everybody only did their own bit in the old curriculum. They were used to it on their own. The challenges were to get everybody engaged, although it did not bring people sufficiently along, so now 10 years down the line we see the cracks developing... people now revert back to what they had before... (U6)

We tend to think of it in a very fragmented way, because 
of the arrangement of the programme across three schools. For the first three years the programme are very much PBL based, it is broken up into themes and there are theme manuals... But the clinical years, I think it is still like the conventional blocks, it probably needs more defining for later years... for instance some details do not belong in the undergraduate curriculum programme, we got to take it out and instruct the specialist so that we do not waste time teaching it... (U4)

The mere fact that institutions have structures in place to attend to curriculum issues does not necessarily imply that all academic staff members are engaged in and knowledgeable about curriculum matters:

I think mapping is important because we do not know what is going on in the curriculum, not even I know what is going on in the first, second and third year and I am the one person in the department that knows the most because I go to the undergraduate programme committee meetings... (translated U8)

To avoid resistance to change among stakeholders, which could stall curriculum mapping, one institution warned against mapping the entire curriculum and advised that institutions should rather use a discipline-based mapping approach, but others differed and asserted that the curriculum should 'belong' to all academics in all disciplines, and that mapping on an electronic platform will facilitate ownership, regardless of committees or the position of an individual.

The way that I think that will probably be a better way to do it and there is actually now much more momentum for it is to actually look at mapping by department or by a discipline ... because people are in different places, depending on the change-readiness of the group you may get completely stalled because one or two disciplines are not interested in mapping anything... (U2)

Whatever you do with regards to the curriculum and mapping... it should belong to the institution so there is always continuity and 10 years down the line people will be able to work with it; because what was done in the past, curricula were owned by HODs or people who knew the curriculum, certain committees only, so if somebody left, when we wanted to review the curriculum it was like redoing the whole... because we did not know the history... but when you have an electronic platform, it is all there, it is very visible, it is easy to change, and it is institutional, it belongs to us all... (U7)

Everybody should use it, unless all have uploaded their data, there will be a void... (U7).

\section{Theme III: Challenges Associated with Curriculum Implementation}

Participants enumerated various challenges they had experienced during the implementation of their current curricula and identified two sub-themes under this category. The first sub-theme includes challenges related to the curriculum itself, and responses indicated a need for a systematic approach to curriculum management. Many of the institutions agreed that curriculum mapping could be a solution to these problems. Some of the concerns raised were about integrated curricula and facilitators from various backgrounds who were not working together to allow the curriculum contents to be coherent, the apparent information overload of the curriculum, the inability of course facilitators to reach consensus on what constitute 'core curriculum' and the unintended consequences of assessment which seemed to have caused some students not to value certain curricula content:

One of the reasons why there is such a cry and a desperate need for a curriculum map, is because the $M B C h B$ programme has become so complex because of $P B L$ and integrated learning and all the rest of it; so now because you have 20 people teaching different aspects of the same thing in one week it is a very real worry that some of them will do the same thing and none of them will actually teach something else that the students also need... (U2)

With integrated exams, one of the problems my colleagues over the years said, we had great integrated exams and the student can say, that's right I don't really need to know physiology, as long as I can pass the cluster and be able to get 50\% I will be okay... And as soon as you say, no you need a sub-minimum for this and that... then they say it is not integrated anyway (laugh), so there are many problems... (U4)

I said the lists are far too long, what I want you to do now is to put just the core ones, the topics that are nonnegotiable in a table on the left hand side and anything else that you really think is important can go on the right hand side... and the reason I did that is because people got incredibly angry about trying to make their list shorter... they said I'm (dumbing) down the curriculum and I'm throwing away the discipline and it is irresponsible and all sorts of interesting things were said so we are still very, very far from a practical, manageable, un-overloaded curriculum and it's kind of a work in progress... (U2)

When I took over we were involved with one of the blocks where interdisciplinary education was piloted, but then they started to abuse us heavily, because they also had too few staff and then we were pushed into all sorts of areas which are not actually our specialty, but you just get an e-mail that instructs you that you will present the next symposium. This should not be happening, and maybe a map will define what the collaboration should look like... (translated U8)

The second sub-theme of challenges revolved around political pressure to increase student numbers, the shortage of clinical teaching staff and service delivery demands by the employer which put additional strain on the already limited human resources. Once again, the feeling of being overwhelmed was expressed by the respondents: 
Especially for the clinical years, the fact that academic staff is employed by the province and the bulk of their responsibilities entails service delivery, and as with many other institutions, we have a shortage of staff and resources which impacts negatively on the ability to also teach... our main problem relates to human resources... you know there are departments with only one consultant, then he is also the head and might not even have a person providing administrative support... so it becomes very difficult under these type of circumstances to do your best... (translated U3)

In this country we really are at a bit of a crossroads... I believe there is a major need for re-curriculation... due to changes... and what has changed is, one we are under pressure from minister of health to double our student intake... and two... now we've got over a 1000 students returning from Cuba per year shortly.... there are over 1000 South African students who studied in China and elsewhere, coming back.... so in other words we have to start preparing our training programmes to also accommodate students returning from Cuba, students returning from China as well as our indigenous students and they have to be doubled anyway... (U4)

\section{DISCUSSION}

Curriculum mapping is an essential strategy of curriculum evaluation, management, and quality assurance strategy; therefore, it is necessary for all institutions offering medical programme to have access to an electronic mapping platform due to its inherent multiple benefits [1], [5], [6], [9]. While none of the South African medical institutions had a fully developed mapping platform at the time of the research, they all possessed templates and matrices that showed graphical or tabular representations of their curricula on paper or available in soft copies accessible through computer hardware. Others have their curricula displayed in narrative form using the paper-based formats which are usually referred to as learning guides or course handbooks. Although the modality of curriculum documentation varied among the institutions, all of them have the same goal.

There seem to be a great deal of awareness of curriculum mapping among these institutions as indicated by the state of readiness of some institutions [9]. Some have embarked on the actual process of establishing electronic mapping platform for their curriculum prior to this study, due to the limitations of paper documentation of an entire curriculum. A couple of the medical schools had started a computer-based alternatives for their preclinical curriculum and intended to fully expand into a web-based platform that will allows for connecting and linking the complex relationships between the various elements in their curriculum. This is a positive development and it is expected that other medical schools would follow suit in terms of developing full electronic mapping platforms as they indicated during the interviews. The issue of resistant to change in curriculum management more pronounced among academics within the clinical disciplines who are involved in curriculum planning was described as the reason why only certain role players have access to the 'big picture' of their curriculum. This feeling of disconnectedness by academic stakeholders is a major cause of curriculum stagnation, and this happens when academics have a sense of exclusive ownership of curriculum content [17]. Staff attitude is most likely to be influenced by curriculum mapping process, once the process ensures that all staff understands the value of mapping and they become engaged with the process.

According to the literature, mapping is an ongoing and iterative process, to be used as a tool for curriculum review, it needs commitment by everybody, regardless of level or seniority, therefore academic stakeholders from all disciplines and integrated themes need to be involved on an ongoing basis in mapping of their particular modules [1], [3], [6], [13]-[15]. Furthermore, some of the challenges associated with curriculum implementation described by the participants are not unique to South Africa. Studies have shown that changes in systems of healthcare delivery and advances in medicine and technology will put more pressure on the medical curriculum in order for it to respond to the needs of the society [4], [18]-[21]. Some of the problems outlined by the participants were consequences of not having a mapping platform. It is envisaged that implementation of curriculum mapping will address some of the structural problems; mapping has been proven to assist in identifying redundancies and unnecessary duplications within the curriculum [22]-[24]. The most import thing is to make sure the mapping process is fluid and dynamic such that it is adaptable to the changing needs of the society that the institution is mandated to serve [25].

\section{CONCLUSION}

With the call for greater social accountability among medical schools getting global recognition; the benefits of tailoring medical education to the need of the community that an institution is mandated to serve cannot be overemphasized [13], [19]. It is therefore the responsibility of the medical schools to ensure that their curricula are well aligned such that they produce doctors with professional attributes who share in the social accountability vision of the university and are prepared to address the health needs of their community. This study provides a snapshot information on the status of curriculum mapping of medical programmes in South Africa, although the mapping process was in its infancy stage during this research, it appeared the medical schools are in tune with global trends in undergraduate medical education. The fact that no medical school had a fully developed electronic mapping platform at the time of this study merely indicated that curriculum mapping was not their priority over the past decade. Nevertheless, all the institutions have evidence of curriculum documentation, strategy of curriculum review and it is encouraging that many of the medical schools were in the process of constructing curriculum mapping platforms. The major concern was that no mention of collaboration among the institutions was made in the development of such a mapping platform. It is therefore likely that different mapping software, taxonomies, and outcome frameworks will be used by the institutions. This could be a potential barrier to benchmarking and collaboration among the medical schools in future [5], [7], [15], [25]. Additional research on the characteristic features 
of mapping platforms that would be developed by all the institutions is highly recommended.

\section{ACKNOWLEDGMENT}

The authors would like to thank Prof Treadwell for her assistance and Dr Uys in confirming analytical coding. The time commitment and valuable information shared by the participants are well appreciated.

\section{REFERENCES}

[1] Harden, RM. AMEE Guide no. 21: Curriculum mapping: A tool for transparent and authentic teaching and learning. Medical Teacher 2001, 23(2):123-137.

[2] Prideaux, D. Curriculum development in medical education: From acronyms to dynamism. Teaching and Teacher Education 2007 23(3):294-302.

[3] Steketee, C. Prudentia: A medical school's solution to curriculum mapping and curriculum management. Journal of University Teaching and Learning Practice 2015, 12(4). http://ro.uow.edu.au/jutlp/vol12/iss4/9

[4] Balzer, F. Bietenbeck, A. Spies, C. Dittmar, M., Lehmann, L. Sughiharto, F \& Ahlers, O. How we avoid patient shortage with an integrated analysis of learning objectives and clinical data during development of undergraduate medical curricula. Medical Teacher 2015, 37(6):533-537.

[5] Balzer, F., Hautz, W.E., Spies, C., Bietenbeck, A., Dittmar, M. Sugiharto, F., Lehmann, L., Eisenmann, D., Bubser, F., Stieg, M., Hanfler, S., Georg, W., Tekian, A. \& Ahlers, O. Development and alignment of undergraduate medical curricula in a web-based, dynamic Learning opportunities, objectives and outcome platform (LOOOP). Early online version. Medical Teacher 2016, 38(4).

[6] Davis, MH. \& Harden, RM. Planning and implementing an undergraduate medical curriculum: The lessons learned. Medical Teacher 2003, 25(6):596-608.

[7] Blaum WE, Jarczweski A, Balzer F, Stötzner P, Ahlers O. Towards Web 3.0: taxonomies and ontologies for medical education -- a systematic review. GMS Z Med Ausbild. 2013;30(1):Doc13. doi: $10.3205 / \mathrm{zma} 000856$.

[8] Britton, M. Letassy, N. Medina, MS \& Er, N. A curriculum review and mapping process supported by an electronic database system. American Journal of Pharmaceutical Education 2008, 72(5):99. http://www.ncbi.nlm.nih.gov/pmc/articles/PMC2630156.

[9] Treadwell, I. Ahlers, O \& Botha GC. Initiating curriculum mapping on the web-based, interactive learning opportunities, objectives, and outcome platform (LOOOP). African Journal of Health Professions Education 2019;11(1):27-31.

[10] Ellaway, R. Albright, S. Smothers, V. Cameron, T. \& Willett, T. Curriculum inventory: Modelling, sharing, and comparing medical education programs. Medical Teacher 2014, 36(3):208-215.

[11] Bansal, P., Christensen, L. \& Leinster, S. Module 2: Organizing a selfreview. In: J. Grant (ed.). Distance learning resources for medical education: Theme 1: Self review and accreditation. The Open University, 2009.

[12] Health Professions Council of South Africa. Questionnaire for selfassessment of faculties/schools for undergraduate education and training of medical doctors, dentists, and clinical associates. HPCSA: May 2015: Pretoria.

[13] Oliver, B. Jones, S. Ferns, S. \& Tucker, B. Mapping curricula: Ensuring work-ready graduates by mapping course learning outcomes and higher order thinking skills. (Paper presented at the Evaluations and Assessment Conference, Brisbane 2007). http://c2010.curtin.edu.au/local/docs/paper3.pdf.

[14] Watson, EG. Moloney, PJ. Toohey, SM. Hughes, CS. Mobbs, SL. Leeper, JB \& McNeil, HP. Development of eMed: A comprehensive, modular curriculum-management system. Academic Medicine 2007, $82(4): 351-360$
[15] Willett, TG. Current status of curriculum mapping in Canada and the UK. Medical Education 2008, 42(8):786-793

[16] Braun, V. \& Clarke, V. Using thematic analysis in psychology. Qualitative Research in Psychology 2006, 3(2):77-101.

[17] Davenport, N. C., Spath, M. L. and Blauvelt, M. J. “A Step-by-Step Approach to Curriculum Review." Nurse Educator 2009, 34(4): 181185 .

[18] Boelen, C. \& Woollard, B. Social accountability and accreditation: A new frontier for educational institutions. Medical Education 2010 , 43(9):887-894

[19] Frenk, J., Chen, L., Bhutta, Z.A., Cohen, J., Crisp, N., Evans, T. Fineberg, H., Garcia, P., Ke, Y., Kelley, P., Kistnasamy, B., Meleis, A., Naylor, D., Pablos-Mendez, A., Reddy, S., Scrimshaw, S., Sepulveda, J., Serwadda, D.\& Zurayk, H. Health professionals for a new century: Transforming education to strengthen health systems in an interdependent world. Lancet 2010, 376(9756):1923-58.

[20] Harden, R.M. \& Hart, I.R. An international virtual medical school (IVIMEDS): The future for medical education? Medical Teacher 2002 24(3):262-267.

[21] Pugsley, L. \& McCrorie, P. Improving medical education: Improving patient care. Teaching and Teacher Education 2007, 23(3):314-322.

[22] Litaker, D., Cebul, R.D., Masters, S., Nosek, T., Haynie, R. \& Smith, C.K. Disease prevention and health promotion in medical education: reflections from an academic health center. Academic Medicine 2004 79(7):690-696

[23] Plaza, C.M., Draugalis, J.R., Slack, M.K., Skrepnek, G.H. \& Sauer, K.A. Curriculum mapping in programme assessment and evaluation. American Journal of Pharmaceutical Education 2007,71(2):20.

[24] Sanchez-Reilly, S. \& Ross, J.S. Hospice, and palliative medicine Curriculum evaluation and learner assessment in medical education. Journal of Palliative Medicine 2012, 15(1):116-122.

[25] Uchiyama KP \& Radin, JL. Curriculum Mapping in Higher Education: A Vehicle for Collaboration." Innovative Higher Education 2009, 33 271-280.

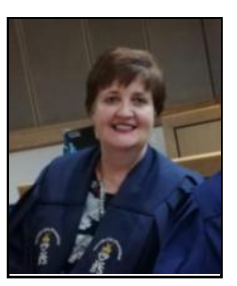

Ms. Gerda C. Botha, MA (Counseling Psych) MPhil (HSE) is the Programme Leader of the Practice of Medicine integrated module of the MBChB curriculum at Sefako Makgatho Health Sciences University, South Africa. She has extensive experience in curriculum design and academic planning of undergraduate medical curriculum. She is a member of the university's Academic Planning committee (APCDC) and the Curriculum Development Committee (CDC). She is also seasoned in the design and developments of decentralized platforms for training and early patient exposure for undergraduate medical students. Her research interests are mainly in health professional education, focusing on curriculum mapping, module integration in medical education, teaching and assessment modalities, and inter-professional medical education.

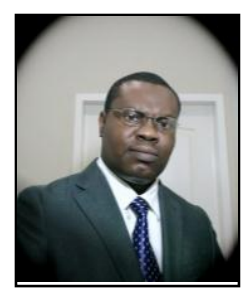

Dr. Adegoke O. Adefolalu, $M B C h B M P H$ PhD FRSPH (UK) is with the School of Medicine at Sefako Makgatho Health Sciences University, South Africa, where he teaches Epidemiology and Research Methods within the Practice of Medicine integrated programme of the MBCHB curriculum. A Public health physician with interest in clinical education, some of his major research interests include clinical epidemiology, health behaviour and health determinants, international health, and curriculum integration in medical education. Dr Adefolalu is an established researcher; he is associate editor of two scientific publications and serves as reviewer for many medical journals. An astute health advocate, he mentors undergraduate and postgraduate students, and he is actively involved in faculty development. 